\title{
Progress of implementation of the World Health Organization strategy for HIV drug resistance control in Latin America and the Caribbean
}

\author{
Giovanni Ravasi, ${ }^{1}$ Noreen Jack, ${ }^{2}$ Mónica Alonso Gonzalez, ${ }^{3}$ \\ Omar Sued, ${ }^{3}$ María Dolores Pérez-Rosales, ${ }^{4}$ Bertha Gomez, ${ }^{5}$ \\ Marcelo Vila, ${ }^{6}$ Amalia del Riego, ${ }^{2}$ and Massimo Ghidinelli ${ }^{3}$
}

Suggested citation Ravasi G, Jack N, Alonso Gonzalez M, Sued O, Pérez-Rosales MD, Gomez B, et al. Progress of implementation of the World Health Organization strategy for HIV drug resistance control in Latin America and the Caribbean. Rev Panam Salud Publica. 2011;30(6):657-62.

ABSTRACT By the end of 2010, Latin America and the Caribbean (LAC) achieved 63\% antiretroviral treatment (ART) coverage. Measures to control HIV drug resistance (HIVDR) at the country level are recommended to maximize the efficacy and sustainability of ART programs. Since 2006, the Pan American Health Organization has supported implementation of the World Health Organization (WHO) strategy for HIVDR prevention and assessment through regional capacity-building activities and direct technical cooperation in 30 LAC countries. By 2010, 85 sites in 19 countries reported early warning indicators, providing information about the extent of potential drivers of drug resistance at the ART site. In 2009, $41.9 \%$ of sites did not achieve the WHO target of 100\% appropriate first-line prescriptions; $6.3 \%$ still experienced high rates (> 20\%) of loss to follow-up, and $16.2 \%$ had low retention of patients $(<70 \%)$ on first-line prescriptions in the first year of treatment. Stock-outs of antiretroviral drugs occurred at $22.7 \%$ of sites. Haiti, Guyana, and the Mesoamerican region are planning and implementing WHO HIVDR monitoring surveys or threshold surveys. New HIVDR surveillance tools for concentrated epidemics would promote further scale-up. Extending the WHO HIVDR lab network in Latin America is key to strengthening regional lab capacity to support quality assured HIVDR surveillance. The WHO HIVDR control strategy is feasible and can be rolled out in LAC. Integrating HIVDR activities in national HIV care and treatment plans is key to ensuring the sustainability of this strategy.

Key words HIV; drug resistance; epidemiologic surveillance; world strategies; regional strategies; Latin America; Caribbean region.

Pan American Health Organization, Brasilia, Brazil. Send correspondence to: Giovanni Ravasi, ravasigi@paho.org

2 Pan American Health Organization, HIV Caribbean Office, Port of Spain, Trinidad and Tobago.

Pan American Health Organization, Washington, DC, United States of America.

4 Pan American Health Organization, San Salvador, El Salvador.

5 Pan American Health Organization, Bogotá, Colombia.

6 Pan American Health Organization, Buenos Aires, Argentina.
Latin America and the Caribbean (LAC) experienced an important scaleup of antiretroviral treatment (ART) in the past decade, with a total of 521000 people on therapy and estimated coverage of $63 \%(57 \%-73 \%)$ as of December 2010 (1). As observed in industrialized countries with a long history of ART use and high treatment coverage, the emer- gence and transmission of HIV drug resistance (HIVDR) is likely to increase and become a challenge for the effectiveness and sustainability of national ART programs in LAC (2).

The Pan American Health Organization (PAHO)/World Health Organization (WHO) recommends that HIVDR control strategies be integrated within 
each country's HIV prevention, treatment, and care programs. WHO developed a global HIVDR prevention and assessment strategy (Table 1), with normative documents available on the Web (www.paho.org/HIVDR, www. who.int/hiv/topics/drugresistance/ en/) (3).

The purpose of the WHO HIVDR strategy is to minimize the emergence of drug resistance, prolong first- and second-line ART effectiveness, and maximize the quality of life of people living with HIV by supporting optimal ART program functioning through evidencebased quality improvement strategies. As of mid 2011, up to 50 countries worldwide had implemented WHOrecommended HIVDR early warning indicators (EWIs), 13 countries had implemented HIVDR monitoring surveys, and 22 had implemented threshold surveys for surveillance of transmitted resistance (1). The objective of this report is to present the progress of implementation of the WHO HIVDR strategy in LAC with general recommendations for scale-up of sustainable HIVDR prevention and assessment activities in the region.

\section{ROLLOUT OF HIVDR STRATEGY IN LAC}

The WHO HIVDR strategy was introduced in LAC in 2006 through a

\section{TABLE 1. Elements of World Health Organization HIV drug resistance prevention and assessment strategy (3)}

a. Formation of a national HIVDR working group and development of a 3- to 5-year work plan and budget

b. Regular assessment of HIVDR early warning indicators from all ART sites (or a selection of representative ART sites)

c. HIVDR monitoring surveys to monitor HIVDR prevention and associated factors at sentinel ART sites

d. Threshold surveys for surveillance of transmitted HIVDR among recently infected individuals and in geographic areas where ART has been widespread for 3 years or more

e. Development of a national HIVDR database.

f. Designation of a national or regional WHOaccredited HIVDR genotyping laboratory

g. Review of and support for HIVDR prevention activities

h. Preparation of an annual HIVDR report and recommendations

HIVDR: HIV drug resistance, ART: antiretroviral treatment, WHO: World Health Organization.
TABLE 2. Pan American Health Organization/ World Health Organization HIV drug resistance workshops in Latin America and the Caribbean: 2006-2010

a. Fort-de-France, Martinique, 10-12 May 2006: First Workshop on the Development of a Caribbean Strategy for the Prevention, Surveillance, and Monitoring of HIV Drug Resistance

b. Port of Spain, Trinidad and Tobago, 23-26 January 2007: Caribbean HIV Drug Resistance (HIVDR) Monitoring and Surveillance Training Workshop

c. Rio de Janeiro, Brazil, 26-28 November 2007: Latin American Workshop on HIV Drug Resistance Prevention, Surveillance, and Monitoring

d. Port of Spain, Trinidad and Tobago, 18-21 November 2008: Regional Meeting Toward the Implementation of HIV Drug Resistance Strategies in the Caribbean

e. Port of Spain, Trinidad and Tobago, 20-22 October 2009: Prevention of HIV Drug Resistance (HIVDR) in the Caribbean: Adherence Strategies, HIVDR Early Warning Indicators, and Use of Patient Monitoring Tools

f. Port of Spain, Trinidad and Tobago, 21-23 June 2010: Simplifying ART reporting including early warning indicators in the Caribbean

g. San Salvador, EI Salvador, 5-7 July 2010: HIV drug resistance and patient monitoring system meeting of Central America and Mexico

h. Bogotá, Colombia, 11-12 November 2010: Workshop on HIV resistance to antiretrovirals

number of regional and subregional capacity-building activities (Table 2) with the objective of raising awareness about the challenge of HIVDR control from a public health perspective, advocating for the implementation of national HIVDR control strategies, presenting the WHO HIVDR prevention and assessment package, and evaluating the feasibility of its implementation in LAC. All countries in the region participated in these training, consensus-building, and experiencesharing activities.

Between 2006 and 2011, direct technical cooperation and in-country training for the development and implementation of national plans for HIVDR prevention and assessment were provided to 30 countries: Anguilla, Antigua and Barbuda, Argentina, Bahamas, Barbados, Belize, Bolivia, Brazil, Chile, Colombia, Costa Rica, Dominica, Dominican Republic, Ecuador, El Salvador, Grenada, Guatemala, Guyana, Haiti, Honduras, Jamaica, Montserrat, Nicaragua, St. Kitts and Nevis, St. Lucia, St. Vincent and the Grenadines, Suriname, Trinidad and Tobago, Uruguay, and Venezuela.

\section{NATIONAL WORKING GROUPS}

WHO recommends that the HIV/ AIDS national program, based at the ministry of health, support the creation of a national HIVDR working group to develop and coordinate a national HIVDR control strategy. HIVDR working groups usually include ART program officers from different technical areas (treatment and care, surveillance, monitoring and evaluation), epidemiologists, HIV clinicians and researchers, lab specialists, civil society, and national and international partner organizations.

PAHO facilitated and directly supported the formation and ongoing technical meetings of HIVDR working groups in LAC for planning and implementing national HIVDR control strategies. National HIVDR working groups are fully functioning in up to 14 countries, and in some cases ad hoc working groups have been formed to coordinate implementation of EWIs.

Countries that maintained active and technically strong working groups, with formal recognition by national authorities, have demonstrated greater capacity for development and timely implementation of their HIVDR control strategies. In addition, active involvement of national and international partners in HIVDR working groups contributed to timely planning and implementation of activities by sharing start-up costs and facilitating technical collaboration.

\section{EARLY WARNING INDICATORS}

EWIs are ART site-based tools for HIVDR prevention and quality assurance to assess the extent to which sites are optimally functioning to prevent resistance (4). EWIs evaluate programmatic factors known to be associated with the emergence of resistance to antiretroviral (ARV) drugs at the ART site level. These factors include ARV drug-prescribing practices, loss to follow-up and retention of patients on first-line ART during the first year of ART, on-time ARV drug pickup and appointment keeping, drug supply continuity, adherence to treatment, and suppression of viral load. EWI monitoring generates strategic information to optimize ART site and national ART program functioning through evidence-based recommendations.

As of December 2010, 21 countries implemented EWI monitoring in a repre- 
sentative selection of ART sites or ad hoc pilot HIV clinics (Argentina, Bahamas, Barbados, Belize, Colombia, Dominica, Dominican Republic, El Salvador, Grenada, Guatemala, Guyana, Haiti, Honduras, Jamaica, Montserrat, Nicaragua, St. Kitts and Nevis, St. Vincent and the Grenadines, St. Lucia, Suriname, and Venezuela) and 19 countries reported EWI results from a total of 85 ART sites (Table 3).

Preliminary EWI results, presented in Table 3, highlight important gaps in ART and HIV care delivery which could contribute to the development of drug resistance. Low levels of compliance with national guidelines in ART prescribing practices was observed throughout the reporting period (cohorts of patients initiating ART in 2007, 2008, and 2009), with fewer than $50 \%$ of sites achieving the WHO target of $100 \%$ first-line prescriptions in line with national or international guidelines. The extent of loss to follow-up of patients during the first year of treatment varied greatly among countries and over time, with $6.3 \%$ of sites assessed in 2009 still experiencing high default rates (> 20\%) during the first year of treatment. Retention of first-line ART at 12 months of treatment seemed to improve over time in the subsets of ART sites selected for EWI monitoring in the reporting period, but $16.2 \%$ of sites in 2009 still reported retention below the WHO target (70\%). EWI 6 results for drug supply continuity showed that stock-outs of ARV drugs persist in LAC (EWI 6b), even though the impact of drug shortages on ARV prescribing and dispensing practices may be minimum (EWI 6a); very few sites selected this version of the indicator.

Table 3 presents only the four indicators with the higher reporting rate during the selected period (2007-2009); very few ART sites were able to collect data and report EWI 4 (percentage of on-time drug pickup), EWI 5 (percentage of on-time appointment keeping), EWI 7 (percentage of patients with 100\% adherence), and EWI 8 (percentage with viral load suppression at 12 months). Lack of documentation, low coverage of viral load monitoring, and inadequate records of drug pickups and appointment keeping made it difficult to collect these proxy indicators of adherence. In addition, a vast majority of ART sites in the region do not usually perform direct standardized adherence measurements.

Through the experience of EWI monitoring in LAC a number of issues related to the quality of medical and pharmacy record systems were identified. Incomplete patient information, fragmented information systems, and poor quality of data recording and data entry in electronic systems were encountered in most countries during the planning and

TABLE 3. Summary of four HIV drug resistance early warning indicator results in Latin America and the Caribbean, 2007-2009a

\begin{tabular}{|c|c|c|c|c|}
\hline \multirow[b]{2}{*}{ HIVDR early warning indicator ${ }^{b}$} & \multirow{2}{*}{$\begin{array}{l}\text { WHO } \\
\text { target, \% }\end{array}$} & \multicolumn{3}{|c|}{ Sites meeting WHO target, \% } \\
\hline & & 2007 & 2008 & 2009 \\
\hline $\begin{array}{l}\text { EWI 1a: Percentage of patients initiating ART during a } \\
\text { selected time period who are initially prescribed, or who } \\
\text { initially pick up from the pharmacy, an appropriate first-line } \\
\text { ART regimen }\end{array}$ & 100 & $\begin{array}{c}47.6 \\
(20 / 42)\end{array}$ & $\begin{array}{c}29.3 \\
(12 / 41)\end{array}$ & $\begin{array}{c}41.9 \\
(18 / 43)\end{array}$ \\
\hline $\begin{array}{l}\text { EWI 2: Percentage of patients initiating ART in a selected } \\
\text { time period who are lost to follow-up during the } 12 \text { months } \\
\text { after starting ART }\end{array}$ & $\leq 20$ & $\begin{array}{c}78.6 \\
(33 / 42)\end{array}$ & $\begin{array}{c}62.5 \\
(10 / 16)\end{array}$ & $\begin{array}{c}93.7 \\
(15 / 16)\end{array}$ \\
\hline $\begin{array}{l}\text { EWI } 3 \text { a: Percentage of patients initiating ART during a } \\
\text { selected time period who are taking an appropriate first- } \\
\text { line ART regimen } 12 \text { months later }\end{array}$ & $\geq 70$ & $\begin{array}{c}69.8 \\
(30 / 43)\end{array}$ & $\begin{array}{c}73.5 \\
(25 / 34)\end{array}$ & $\begin{array}{c}83.8 \\
(31 / 37)\end{array}$ \\
\hline $\begin{array}{l}\text { EWI 6b: Percentage of months in a designated year in } \\
\text { which there were no ARV drug stock-outs }\end{array}$ & 100 & $\begin{array}{c}48.5 \\
(16 / 33)\end{array}$ & $\begin{array}{l}36.4 \\
(4 / 11)\end{array}$ & $\begin{array}{c}77.3 \\
(17 / 22)\end{array}$ \\
\hline $\begin{array}{l}\text { EWI 6a: Percentage of patients on first-line ART whose } \\
\text { regimen was stopped, modified, or incompletely dispensed } \\
\text { at the pharmacy due to ARV stock-outs or shortages } \\
\text { during a designated year }\end{array}$ & 0 & $\begin{array}{l}80.0 \\
(4 / 5)\end{array}$ & $\begin{array}{l}100.0 \\
(4 / 4)\end{array}$ & $\begin{array}{l}100.0 \\
(1 / 1)\end{array}$ \\
\hline \multicolumn{5}{|c|}{$\begin{array}{l}\text { HIVDR: HIV drug resistance, WHO: World Health Organization, EWI: early warning indicator, ART: antiretroviral treatment } \\
\text { ARV: antiretroviral. } \\
\text { a Summary results from } 85 \text { ART sites in } 19 \text { countries in Latin America and the Caribbean (Bahamas, Barbados, Belize, Co } \\
\text { lombia, Dominica, Dominican Republic, El Salvador, Grenada, Guatemala, Guyana, Haiti, Honduras, Jamaica, Montserrat } \\
\text { Nicaragua, St. Kitts and Nevis, St. Vincent and the Grenadines, St. Lucia, Suriname) that reported EWI as of December } 2010 \\
\text { b EWI } 2008 \text { version. }\end{array}$} \\
\hline
\end{tabular}

pilot phase. Collection of data on EWIs created opportunities for medical and pharmacy data record systems to be revised, updated, improved, and implemented in a standardized manner at the country level as recommended by international consensus guidelines on patient monitoring (5). Such operations may have initially delayed the generation of results, but they have been of substantial importance to strengthen national capacity for ART program monitoring and evaluation and data quality assurance to generate reliable results.

\section{THRESHOLD SURVEYS FOR TRANSMITTED HIVDR}

In the past decade, transmitted resistance surveys have been conducted in many countries in Latin America, and evidence of low $(<5 \%)$ to moderate $(5 \%-15 \%)$ prevalence of resistance among newly diagnosed and ARV-naive individuals has been documented (6-16). Nevertheless, transmitted resistance surveillance in LAC has been performed with different methodologies-targeting different populations, generally over long periods of time ( $>12$ months), and using different selection criteria and definitions for key concepts such as "recent infection" and "recent diagnosis." Such substantial methodological differences make it difficult to compare transmitted resistance data among countries in the region and even within countries over time, highlighting the need to adopt standardized methodologies.

WHO-recommended HIVDR threshold surveys are population-based surveys designed to classify the prevalence of transmitted drug resistance among recently infected individuals at three levels: low $(<5 \%)$, moderate $(5 \%-15 \%)$, and high $(>15 \%)$. The WHO-recommended threshold survey methodology and the truncated sequential sampling method to categorize transmitted resistance are described elsewhere $(17,18)$.

This methodology was used for the first time in Latin America in Mexico in 2004, when a threshold survey was performed at voluntary counseling and testing sites (results not published), and the dried blood spot methodology for HIV genotyping was tested (19). In Brazil, a national HIVDR surveillance study was performed in 2007-2008, which included five threshold surveys conducted in large state capitals (São Paulo, Rio 
de Janeiro, Porto Alegre, Salvador, and Brasilia and Belém) using an adapted version of the WHO method in recently diagnosed HIV patients at ART sites (20). Low transmitted resistance $(<5 \%)$ was estimated in Porto Alegre and Salvador, while intermediate resistance $(5 \%-15 \%)$ was detected in the other three urban areas. While the WHO threshold survey protocol has been widely implemented in the context of generalized epidemics, mostly in the African region, very few countries in Latin America have suitable epidemiological conditions. In 2010, a threshold survey for transmitted resistance was started in Panama in the general population recently infected with HIV according to WHO criteria. In addition, the threshold survey methodology was integrated in a multicountry project for transmitted drug resistance surveillance (Mesoamerican project), which is ongoing in Mexico and selected Central American countries.

\section{HIVDR MONITORING SURVEYS}

HIVDR monitoring surveys are designed to be implemented at representative sentinel ART sites using cohorts of consecutively enrolled patients initiating treatment. Cohorts of 100-150 patients have baseline specimens genotyped to evaluate baseline resistance and a second specimen drawn at 12 months (or at switch from first-line treatment in case of treatment failure) for viral load and genotype, if the viral load is detectable (> 1000 copies/mL). HIVDR monitoring surveys are described elsewhere (21).

In most LAC countries, ART services have been decentralized, and the difficulty of reaching the required survey sample size (100-150) in the expected time (maximum 12 months) and in the expected number of sites in each country (3-10 per year during 3 years) makes it challenging to implement WHO HIVDR monitoring surveys in this region. Only two countries with generalized epidemics (Haiti and Guyana) developed national HIVDR monitoring protocols adapted from the one recommended by WHO. HIVDR monitoring surveys are currently being implemented in Georgetown, Guyana, and Port-au-Prince, Haiti.

\section{HIVDR LABORATORY NETWORK}

The regional capacity to perform HIV genotyping for clinical care and surveil- lance remains concentrated in a few upper-middle-income countries, while access to resistance testing remains generally limited for most lower-middleincome countries in the region. The WHO HIVDR strategy includes a global HIVDR laboratory network established to provide quality assured genotyping to countries implementing HIVDR monitoring and threshold surveys (22).

As of August 2011, 27 laboratories have been accredited, 5 of them in the region of the Americas (23): the Virology and Immunology Service of the Hospital and University Centre in Fortde-France, Martinique; the AIDS Research Program-Immunology Reference Laboratory in Ponce, Puerto Rico; the National Laboratory for HIV Genetics of the Public Health Agency of Canada in Ottawa; the International Laboratory Branch of the Global AIDS Program of the Centers for Disease Control and Prevention in Atlanta, United States of America; and the AIDS and Molecular Immunology Laboratory of the Oswaldo Cruz Institute/Fiocruz in Rio de Janeiro, Brazil. To support the implementation of future HIVDR threshold surveys in Brazil and the Mesoamerican region, three additional laboratories (two in Brazil and one in Mexico) applied for accreditation in 2010 and are being evaluated. The procedures and criteria for the assessing laboratories applying for accreditation to the WHO drug resistance network were published in 2008 and are available on the $\mathrm{WHO}$ and PAHO websites.

\section{CONCLUSIONS}

LAC countries have advanced in the past few years with regard to raising the awareness of HIV / AIDS policymakers about the importance of integrating HIVDR prevention and assessment activities within national strategic plans; building local capacity for implementation of HIVDR prevention, surveillance, and monitoring activities; promoting quality of care at the ART site level as a way to minimize drug resistance; and positioning HIVDR in the public health and research agenda of national HIV/ AIDS programs and academic institutions. Challenges remain with respect to long-term sustainability and effective implementation of national strategies for HIVDR prevention and assessment in the years to come.
From the experience gained in the past few years in LAC countries, the following recommendations are proposed as guidance for future planning and implementation of HIVDR strategies:

- National HIVDR working groups, characterized by interdisciplinary and intersectoral membership, should be formally recognized by ministries of health as advisory committees for national HIV / AIDS programs with regard to drug resistance control strategies.

- Coordination among national HIV/ AIDS programs, HIVDR working groups, and national and international partners should be promoted to guarantee efficiency of resources and harmonized methodology. Timely implementation of HIVDR strategies has been possible through country-based and international partnerships that provide the required technical and financial start-up support; gradual integration of activities within national work plans and budgets is necessary for long-term sustainability.

- Medical and pharmacy information systems should be revised, updated, and standardized at the national level, if necessary, and maintained with data quality assurance strategies. Such systems will provide reliable information for EWI monitoring as well as for any ART program monitoring and evaluation activity.

- Countries should regularly monitor EWIs at all treatment sites, or at representative sites, and integrate these indicators within national monitoring and evaluation strategic plans; EWI reports should be used for continued quality improvement.

- Survey methodology for HIVDR monitoring and surveillance of transmitted resistance should be harmonized to enable appropriate comparisons among countries and over time. The development of regional HIVDR surveillance networks using standardized methodology should be supported. In LAC, threshold surveys were implemented exclusively in pregnant women and the general population, while transmitted HIVDR in most at-risk populations remains unevaluated. To improve the applicability of WHO threshold surveys in the context of concentrated epidemics, a revised methodology is required for transmitted resistance surveillance in most at-risk populations. 
Future progress in the implementation of the WHO HIVDR strategy in LAC should aim at strengthening national working groups and creating new ones, expanding EWI monitoring to new countries or beyond the initial pilot phase, reviewing EWI data quality, presenting results at national and international forums and in peer-reviewed journals, implementing HIVDR monitoring and threshold surveys in selected countries, and expanding the WHO HIVDR laboratory network in LAC. Assessment and prevention of resistance is key to long-term effectiveness and sus- tainability of universal access to ART, and strategies for prevention, monitoring, and surveillance of resistance should be part of the national comprehensive response to the HIV epidemic.

Acknowledgments. The authors acknowledge the invaluable effort of all the persons, partners, and organizations involved in implementing the WHO HIVDR strategy in the LAC region: all PAHO HIV focal points in country offices for their efficient work and constant support; all HIV/AIDS national programs and HIVDR working group members involved in HIVDR activities for their commitment to fighting drug resistance and improving the quality of care for people in their countries living with HIV; specialized, regional, and new candidate laboratories for the WHO HIVDR lab network; the Public Health Agency of Canada for constant support and for being available to provide technical cooperation; the WHO Geneva HIVDR team for its leadership and support; CIDA Canada; and the Bill and Melinda Gates Foundation for financial support.

\section{REFERENCES}

1. World Health Organization, Joint United Nations Programme on HIV/AIDS, and United Nations Children's Fund. Towards universal access: scaling up priority HIV/AIDS interventions in the health sector: progress report 2011. Geneva: WHO, UNAIDS, and UNICEF; 2010. Available from: http://www.who. int/hiv/pub/progress_report2011/en/ index.html Accessed 18 January 2012.

2. Programme Commun des Nations Unies sur le VIH/SIDA, Pan American Health Organization, and United Nations Children's Fund. Retos planteados por la epidemia del VIH en America Latina y el Caribe. Geneva: ONUSIDA, PAHO, and UNICEF; 2009. Available from: http://www.unicef.org/peru/ spanish/RETOS_PLANTEADOS_POR LA_EPIDEMIA_DEL_VIH_2009.pdf Accessed 2 September 2011.

3. Bennett DE, Bertagnolio S, Sutherland D, Gilks CF. The World Health Organization's global strategy for prevention and assessment of HIV drug resistance. Antivir Ther. 2008;13(Suppl 2):1-13.

4. World Health Organization. HIV drug resistance early warning indicators. Geneva: WHO; 2010. Available from: http://www. who.int/hiv/topics/drugresistance/indi cators/en/index.html Accessed 2 September 2011.

5. World Health Organization, Joint United Nations Programme on HIV/AIDS, and U.S. Agency for International Development. Patient monitoring guidelines for antiretroviral therapy (ART). Geneva: WHO, UNAIDS, and USAID; 2006. Available from: http://www. who.int/3by $5 /$ capacity/ptmonguide linesfinalv1.PDF Accessed 2 September 2011.

6. Dilernia DA, Lourtau L, Gomez AM, Ebenrstejin J, Toibaro JJ, Bautista CT, et al. Drug resistance surveillance among newly HIV-1 diagnosed individuals in Buenos Aires, Argentina. AIDS. 2007;21:1355-60.

7. Petroni A, Deluchi G, Pryluka D, Rotryng F, Bortolozzi R, Lopardo G, et al. Update on primary HIV-1 resistance in Argentina: emergence of mutations conferring high-level resistance to nonnucleoside reverse tran- scriptase inhibitors in drug-naive patients. J Acquir Immune Defic Syndr. 2006;42:506-10.

8. Lama JR, Sanchez J, Suarez L, Caballero P, Laguna A, Sanchez JL, et al. Linking HIV and antiretroviral drug resistance surveillance in Peru: a model for a third-generation HIV sentinel surveillance. J Acquir Immune Defic Syndr. 2006;42:501-5.

9. Lloyd B, O'Connell RJ, Michael NL, Michael NL, Aviles R, Palou E, et al. Prevalence of resistance mutations in HIV-1-infected Hondurans at the beginning of the National Antiretroviral Therapy Program. AIDS Res Hum Retroviruses. 2008;24:529-35.

10. Ríos M, Delgado E, Pérez-Alvarez L, Fernández J, Gálvez P, Vázquez de Parga E, et al. Antiretroviral drug resistance and phylogenetic diversity of HIV-1 in Chile. J Med Virol. 2007;79:647-56.

11. Ruibal-Brunet IJ, Cuevas MT, Díaz-Torres H, Villahermosa ML, Noa-Romero E, Vázquez de Parga E, et al. Genotypic resistance mutations to antiretroviral drugs in HIV-1 B and non-B subtypes from Cuba. Rev Panam Salud Publica. 2001;10(3):174-80.

12. Petersen ML, Boily MC, Bastos FI. Assessing HIV resistance in developing countries: Brazil as a case study. Rev Panam Salud Publica. 2006;19(3):146-56.

13. Brindeiro RM, Diaz RS, Sabino EC, Morgado MG, Pires IL, Brigido L, et al. Brazilian Network for HIV Drug Resistance Surveillance (HIV-BResNet): a survey of chronically infected individuals. AIDS. 2003;17:1063-9.

14. Sprinz E, Netto EM, Lima MP, Furtado J, da Eira M, Zajdenverg R, et al. Primary antiretroviral drug resistance among HIV type 1-infected individuals in Brazil. AIDS Res Hum Retroviruses. 2009;25(9):861-7.

15. Pando MA, Gómez-Carrillo M, Vignoles M, Rubio AE, dos Ramos Farias MS, Vila M, et al. Incidence of HIV type 1 infection, antiretroviral drug resistance and molecular characterization in newly diagnosed individuals in Argentina: a global fund project. AIDS Res Hum Retroviruses. 2011;27(1):17-23.

16. Murillo W, Paz-Bailay G, Morales S, Monterroso E, Paredes M, Dobbs T, et al. Transmitted drug resistance and type of infec- tion in newly diagnosed HIV-1 individuals in Honduras. J Clin Virol. 2010;49(4):239-44.

17. Bennett DE, Myatt M, Bertagnolio S, Sutherland D, Gilks CF. Recommendations for surveillance of transmitted HIV drug resistance in countries scaling up antiretroviral treatment. Antivir Ther. 2008;13(Suppl 2):25-36.

18. Myatt M, Bennett DE. A novel sequential sampling technique for the surveillance of transmitted HIV drug resistance by crosssectional survey for use in low resource settings. Antivir Ther. 2008;13(Suppl 2):37-48.

19. Bertagnolio S, Soto-Ramirez L, Pilon R, Rodriguez R, Viveros M, Fuentes $\mathrm{L}$, et al. HIV-1 drug resistance surveillance using dried whole blood spots. Antivir Ther. 2007;12(1):107-13.

20. Inocencio LA, Pereira AA, Sucupira MC, Fernandez JC, Jorge CP, Souza D, et al. Brazilian network for HIV drug resistance surveillance: a survey of individuals recently diagnosed with HIV. J Int AIDS Soc. 2009;12:20.

21. Jordan MR, Bennett DE, Bertagnolio S, Gilks CF, Sutherland D. World Health Organization surveys to monitor HIV drug resistance prevention and associated factors in sentinel antiretroviral treatment sites. Antivir Ther. 2008;13(Suppl 2):15-23.

22. Bertagnolio S, Derdelinckx I, Parker M, Fitzgibbon J, Fleury H, Peeters M, et al. World Health Organization/HIVResNet drug resistance laboratory strategy. Antivir Ther. 2008;13(Suppl 2):49-57.

23. World Health Organization. WHO HIVDR laboratory network annual report for 2010 . Geneva: WHO; 2010. Available from: http:// www.who.int/hiv/topics/drugresis tance/who_hivdr_laboratory_network_ annual_report_2010.pdf Accessed 2 September 2011.

Manuscript received on 10 April 2011. Revised version accepted for publication on 9 September 2011. 
RESUMEN Hacia fines del 2010, América Latina y el Caribe lograron una cobertura de tratamiento antirretroviral de $63 \%$. Se recomienda la ejecución de medidas para controlar la farmacorresistencia del VIH a nivel de país para potenciar al máximo la eficacia y

Progreso en la aplicación de la estrategia de la Organización Mundial de la Salud para el control de la farmacorresistencia del VIH en América Latina y el Caribe la sostenibilidad de los programas de tratamiento antirretroviral. Desde el 2006, la Organización Panamericana de la Salud ha apoyado la aplicación de la estrategia de la Organización Mundial de la Salud (OMS) para la prevención y la evaluación de la farmacorresistencia del VIH mediante actividades regionales de formación de capacidad y de cooperación técnica directa en 30 países de América Latina y el Caribe. En 2010, 85 centros en 19 países notificaron indicadores de alerta temprana y suministraron información acerca del alcance de los posibles impulsores de la farmacorresistencia en los centros de tratamiento antirretroviral. En el 2009, 41,9\% de los centros no lograron la meta de la OMS de $100 \%$ de prescripción de medicamentos de primera línea apropiados; $6,3 \%$ todavía tenían tasas elevadas (> 20\%) de pérdida de seguimiento y 16,2\% tenían una baja retención de pacientes $(<70 \%)$ en tratamiento con antirretrovirales de primera línea en el primer año de tratamiento. Se registraron desabastecimientos de medicamentos antirretrovirales en $22,7 \%$ de los centros. Haiti, Guyana y la zona mesoamericana están planificando y ejecutando estudios de vigilancia de la farmacorresistencia del VIH o estudios del umbral de la OMS. Las nuevas herramientas para la vigilancia de la farmacorresistencia del VIH en las epidemias concentradas permitirán una mejor vigilancia. La ampliación de la red de laboratorios de farmacorresistencia del VIH acreditados por la OMS en América Latina es fundamental para el fortalecimiento de la capacidad de los laboratorios regionales, a fin de de efectuar una vigilancia de la farmacorresistencia del VIH de calidad garantizada. La estrategia para el control de la farmacorresistencia del VIH de la OMS es factible y puede implantarse en América Latina y el Caribe. La integración de las actividades de vigilancia de la farmacorresistencia del VIH con los planes nacionales de atención y tratamiento del VIH es fundamental para garantizar la sostenibilidad de esta estrategia. $\begin{array}{ll}\text { Palabras clave } & \mathrm{VIH} \text {; resistencia a medicamentos; vigilancia epidemiológica; estrategias mundiales; } \\ \text { estrategias regionales; América Latina; región del Caribe. }\end{array}$ 